\title{
Controlling and capturing emissions
}

\author{
Technological civilization often depends on processes that have a significant environmental impact, but emissions \\ control catalysts or porous adsorbent materials can ameliorate these risks.
}

S ometimes bad consequences occur despite good intentions. Take the case of Dr Thomas Midgley Jr for example, a chemical engineer who worked at General Motors in the 1920s. At that time internal combustion engines could suffer from 'knocking', where the fuel/air mixture outside the flame front prematurely ignites. This can potentially damage the engine or reduce the combustion efficiency. Dr Midgley's solution to this problem was to use an additive that suppressed ignition, specifically tetraethyllead. Sadly, the uptake of lead additives in petrol was widespread, leading to decades of emissions of lead compounds with the associated health effects before a general phase-out of the additives started in the 1990s. Midgley later contributed to a second engineering problem - the search for a replacement to the toxic or flammable gases used at the time in refrigeration devices. The Midgley team focussed on the use of alkyl halides as potential replacements, and eventually demonstrated that dichlorodifluoromethane could be used for refrigeration as it was highly volatile but chemically inert. It was only decades later that the effects of this and other chlorofluorocarbons (CFCs) on the ozone layer was determined ${ }^{1}$, leading to a widespread ban on these compounds.

It is an unfortunate fact that many technological processes lead to the emission of harmful or destructive compounds. This is vividly made manifest in the large-scale emissions of $\mathrm{CO}_{2}$ leading to a rise in average worldwide surface temperatures, a trend first predicted by Svante Arrhenius in $1896^{2}$. However, technology can also come to the rescue. In this Focus, we feature two Reviews that discuss the capability of materials for emissions control and capture, and how they can be used to reduce the impact of modern civilization on health or the environment.

Emissions control catalysts allow the transformation of harmful compounds into safe, or at least safer, compounds. As such, they have become an essential component for engine exhausts in the form of catalytic converters. In a Review, Abhaya Datye and Martin Votsmeier outline materials concepts that could lead to significant improvements in performance for the catalytic conversion of hydrocarbons, $\mathrm{CO}$, and $\mathrm{NO}_{x}$, into less harmful $\mathrm{CO}_{2}$.

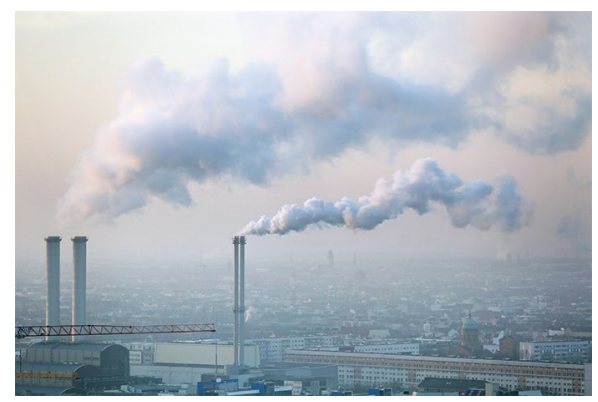

Credit: Agencja Fotograficzna Caro / Alamy Stock Photo

With improving engine efficiency the exhaust temperature decreases, meaning that catalysts able to reach high catalytic conversions even at lower temperatures are required. The potential for encapsulation of catalyst nanoparticles in a protective layer or modified support to enhance durability with temperature are discussed and the prospects of different classes of emerging advanced catalysts, such as microporous oxides or single atom catalysts, are examined. Grand challenges such as NO splitting, low light-off temperatures for $\mathrm{NO}_{x}$ reduction or CO oxidation, reducing or removing the precious metals used in these catalysts, or activating $\mathrm{CH}_{4}$ and so reducing $\mathrm{CO}_{2}$ emissions as this fuel has a higher $\mathrm{H} / \mathrm{C}$ ratio, are also discussed. Finally, in order to progress from the lab to industry, harsh aging conditions should be used to test the aging processes of the catalysts, and each catalyst should be pushed until it fails.

Although the industrial-scale transformation of $\mathrm{CO}_{2}$ emissions, which total over 30 gigatonnes per year, is still in its infancy, this is an active area of research ${ }^{3,4}$. Carbon dioxide can also be sequestered in geographical substrates underground, but in order to do this carbon capture technologies and materials must be refined. In a Review, Jeffrey Long and colleagues discuss the potential of porous materials for the adsorptive separation of $\mathrm{CO}_{2}$ from other gases such as $\mathrm{N}_{2}, \mathrm{O}_{2}$, or water vapour. Unlike aqueous amine solutions - the most advanced $\mathrm{CO}_{2}$ capture technology porous adsorbents do not suffer from volatilization or corrosion issues, and are predicted to be much more energy efficient. Carbon dioxide emissions not just from the power sector but also other significant industrial emitters such as the cement or steel industries, are outlined, as well as stream-specific challenges that need to be overcome. A wide array of adsorbent classes, such as activated carbons, zeolites, silicas, porous organic networks, and metal-organic frameworks are discussed, together with a qualitative assessment of their key metrics for carbon capture applications. Materials scientists need to address lifecycle analysis or the ability to scale production, and mixed gas adsorptions need to be studied in order to understand deactivation mechanisms in the presence of contaminants such as $\mathrm{H}_{2} \mathrm{~S}$. And process engineering must also be considered, with consideration of the structured forms of the adsorbent or reduction of the sorption enthalpy to reduce thermal cycling. To this end, early materials testing using realistic and standardized process conditions is recommended.

Unlike for CFCs, a rapid ban of industrial $\mathrm{CO}_{2}$ emissions seems unfeasible, but there are cautious signs of a growing international consensus for a substantial reduction ${ }^{5}$, which would require investment in materials and processes for carbon capture ${ }^{6}$. Similarly, an instant ban on internal combustion engines will not happen, although targets have been set for phasing them out in cars by the $2030 \mathrm{~s}^{7}$, which will require further improvements in both energy storage technologies and electrical infrastructure. Researchers are working hard on emissions control or capture technologies, and effective deployment of these approaches should clearly be pushed forward.

Published online: 28 July 2021

https://doi.org/10.1038/s41563-021-01076-2

References

1. Farman, J., Gardiner, B. \& Shanklin, J. Nature 315, 207-210 (1985).

2. Arrhenius, S. London, Edinburgh, Dublin Philos. Mag. J. Sci. 41, 237-286 (1896)

3. Nam, D.-H. et al. Nat. Mater. 19, 266-276 (2020).

4. Diercks, C. S., Liu, Y., Cordova, K. E. \& Yaghi, O. M. Nat. Mater. 17, 301-307 (2018).

5. Nat. Energy 6, 567 (2021).

6. Nat. Mater. 20, 713 (2021)

7. Growing momentum: Global overview of government targets for phasing out sales of new internal combustion engine vehicles. Automotive World (11 November 2020); https://go.nature. com/3xvFCLR 